\title{
Tibialis Anterior Tendon: A Reliable Anatomical Landmark Indicating the Ankle Centre. Potential Utility in Extra-Medullary Alignment During Total Knee Replacement
}

\author{
Avadhoot P. Kantak ${ }^{1, *}$ \\ ${ }^{1}$ Trauma and orthopaedic Department, East Surrey Hospital, Redhill, Surrey, United Kingdom \\ "Corresponding author: Avadhoot P. Kantak, 67, Crescent Way, Horley, Surrey, UK. RH6 7LJ. Tel: +44-1293277678, Fax: +44-1737768511, E-mail: dravadhoot1@gmail.com
}

Received 2017 May 14; Revised 2017 July 02; Accepted 2017 July 07.

\begin{abstract}
Background: Extramedullary alignment is a well established surgical technique during total knee replacement. There are different methods to achieve accuracy but variability is quite extensive. To attain uniformity in the surgical technique we have been using the tibialis tendon to align our resection guide. This may prove to be a useful aid for surgeons during knee replacement surgery. Objectives: The purpose of our study was to establish if tibialis anterior tendon represents the centre of ankle joint and if it could be used as an anatomical reference for alignment during knee replacement.

Methods: We designed a retrospective radiological cohort study. We studied sixty MRI scans of normal ankles. The centre of ankle joint was marked as a bisection point of the intermalleolar line at the level of superior surface of the talus. A line was drawn connecting the centre of Achilles tendon to the ankle centre and this was extended anteriorly. This line was found to have a constant relation to the ankle centre and it would simulate the positioning of the standard alignment device used.

Results: The tibialis anterior tendon lies less than $3 \mathrm{~mm}$ medial to the ankle centre in the frontal plane.

Conclusions: We conclude that the tibialis anterior tendon can be used during knee replacement surgery as an accurate alignment guide.
\end{abstract}

Keywords: Total Knee Replacement, Tibialis Anterior Tendon, Coronal Alignment

\section{Background}

Total knee replacement is well regarded as a successful orthopaedic procedure for treatment of painful arthritic knee. It relieves pain and improves knee function in the majority of patients. With advancement in surgical techniques and implant design, the knee replacement has shown a survival of more than 15 years in $90 \%$ of patients $(1,2)$. There are many factors that contribute to failure of knee replacement; and component malalignment is an important one of them. It is therefore important to achieve appropriate position of the components by accurate bony cuts and precise ligament balance. Failure can manifest as aseptic loosening, instability, polyethylene wear or all of these $(3,4)$. Aligning the knee replacement within $3^{\circ}$ of the mechanical axis is associated with reduced wear and optimal implant survival $(5,6)$. Berend et al. (7) reported that the failure of a knee replacement would be increased by 17 times in cases with a tibial varus alignment of more than $3^{\circ}$. Tibial component alignment can be considered as a key step during a knee replacement. Placement of the tibial component at $90^{\circ}$ to the tibial axis is hence universally recommended.

Optimal tibial alignment can be achieved by either in- tramedullary or extramedullary guides. Both these methods have advantages and disadvantages. Intramedullary guides cannot be used in patients with severe post traumatic deformities and patients with excessive tibial bowing (8). These guides are also reported to have increased risk of fat embolism $(9,10)$. Extramedullary guides, on the other hand, allow the surgeon an opportunity to crosscheck their alignment and revise the position of the cutting guides to ascertain accuracy (11). However, the use of extramedullary guides places the onus of responsibility entirely on the surgeon. It demands the surgeon to align the tibial tray perpendicular to the tibial axis. The distal end of the alignment device is determined subjectively. This can cause error in alignment; because the ankle centre is not always easy to identify, especially in the overweight patients who have a significant soft tissue cover to obscure ankle anatomy. It can also be difficult when patients have ankle joint arthritis (12). Using extramedullary guides, it has been reported that only $70 \%$ to $80 \%$ of patients have the tibial component placement within $3^{\circ}$. This suboptimal positioning is despite improvements in surgical techniques and instrumentation $(13,14)$. Studies have described many anatomical landmarks for aligning extramedullary alignment guides but there is wide variation 
in the description of these landmarks among papers (1519). We attempt to prove that the tibialis anterior tendon has a stable relation with the ankle centre and can be utilized in extramedullary alignment technique.

\section{Methods}

An observational study of sixty adult ankle MRI scans was organized. The ankle MRIs were selected from our hospital database retrospectively. Irrespective of the indication for the ankle scan, only the scans reported to be normal by a consultant radiologist were included in the study. 30 female and 30 male MRI scans included. The age ranged from 32 to 81 . Axial cuts at the level of the ankle joint and one proximal to the joint were studied. Ankle centre was mapped by the digital measurement software available with our PACS system. A central point in the transverse section of tibialis anterior tendon was identified on the axial cuts (TA) (Figure 1). The ankle centre was marked as a bisection point of the intermalleolar line at the level of talar dome. To simulate the relation of the ankle centre to the frontal plane, as seen during surgery, we connected the ankle centre to the centre of Achilles tendon and extended this line anterior. This suggested the ankle centre as viewed in coronal plane. The distance between this line [extension of ankle centre (C)] and the tibialis tendon was measured in millimeters and found to be reflective of the relation between ankle centre $(\mathrm{C})$ and tibialis anterior tendon (TA) (Figure 2). If the TA was medial to the centre the measurement was prefixed with $\mathrm{M}$; and for a laterally placed TA the prefix used was $\mathrm{L}$.

\section{Results}

Out of the 60 scans studied, the tibialis anterior tendon (TA) was always found to be medial to the ankle centre (C). The average distance between the TA and C was 1.87 millimetres (range 1.5 to $2.5 \mathrm{~mm}$ ). The $95 \%$ confidence interval for the data was 1.81 to 1.92 (Figure 3 ).

\section{Discussion}

Our study demonstrates that the ankle centre has a constant relation to the tibialis anterior tendon, being just lateral to it. This study further confirms this surgical method. We identify this technique as an excellent adjuvant to other techniques that surgeons use.

The outcome of knee replacement depends on multiple factors. But many studies have stressed the importance of appropriate component alignment as a prime factor.

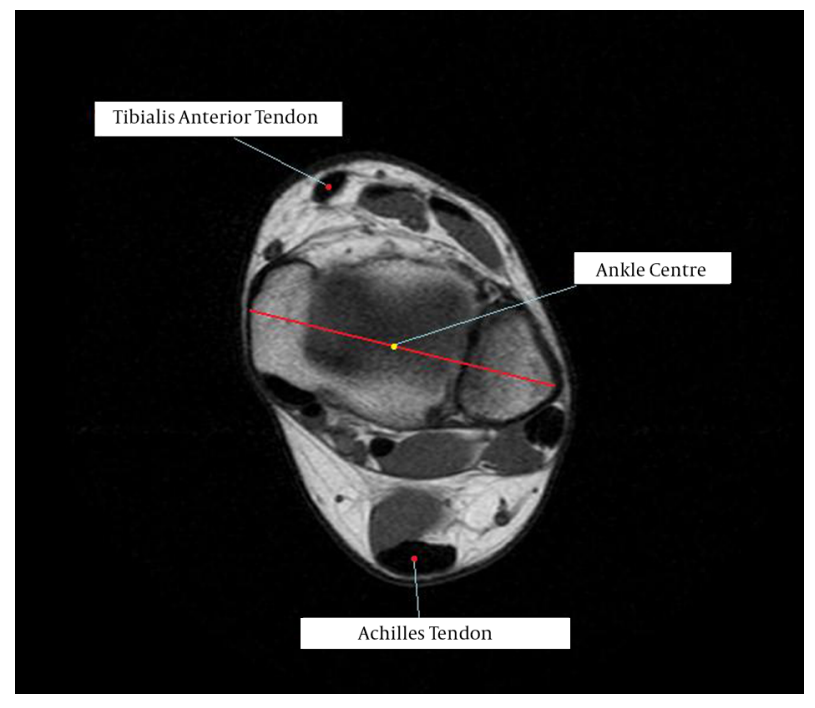

Figure 1. Axial Section at the Level of Talar Dome with Marking for Various Land Marks.

The failure rate is reported to be higher when tibial implants are positioned in varus of less than 86 degrees (20). In the normally aligned knee, $75 \%$ of the joint force passes through the medial compartment; (21) loading is predominantly through the medial compartment even with valgus malalignment (22), excessive tibial varus increases the medial compartment loading. This is a biomechanical disadvantage as the moment across the medial joint increases and leads to worsening of polyethylene wear (23). The tibial component malalignment decides the overall alignment of the knee replacement. It alters the tibiofemoral angle directly. The exact tibiofemoral angle to be achieved post knee replacement is still debated in literature but the recommended values range from $08^{\circ}$ to $12^{\circ}$ of valgus (2429). There are various techniques available to achieve correct alignment. Intramedullary system has limitations in situations like valgus deformity, tibial bowing, and persistent deformity after osteotomy or fracture. In such circumstances the intramedullary guides cannot attain correct tibial cuts $(30,31)$. In such situations extramedullary systems are often preferable (30). In spite of many clinical studies there is no robust evidence to prove if any one system is better than the other. The extramedullary alignment has advantages like reduced risk of fat embolism and intraoperative fracture. It also results in a more reliable cementation as a result of retention of the cement in the metaphyseal area without any diaphyseal extravasations (32).

Computer navigation is one way to reduce error of malalignment. It is a relatively new advancement in joint 


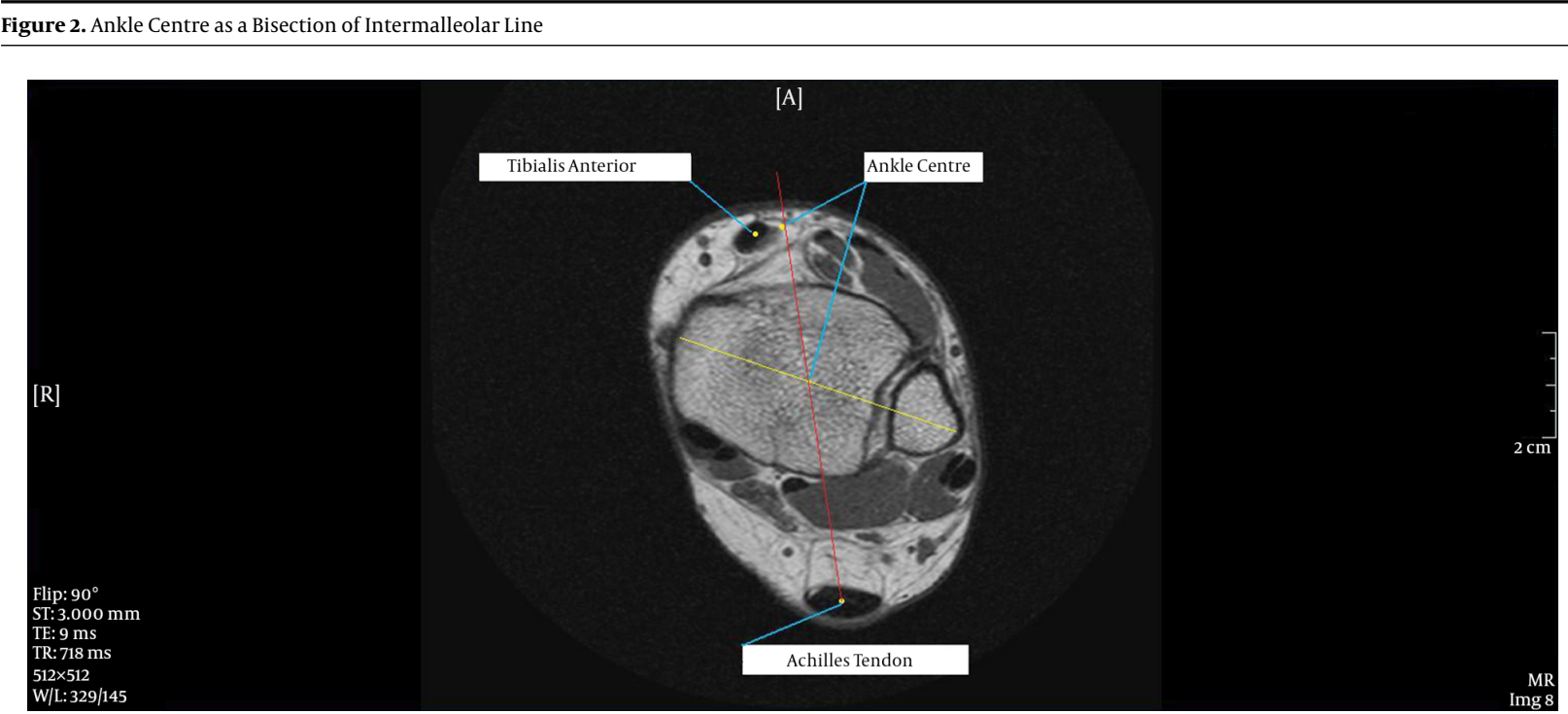

Ankle centre connected to Achilles tendon centre and extended anterior. Distance calculated between ankle centre and tibialis anterior.

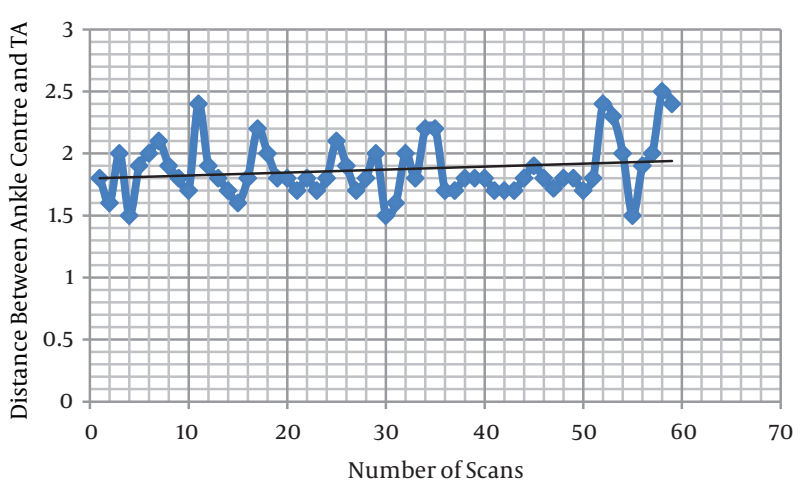

Figure 3. Distribution of Tibialis Anterior Tendon Position on the Scatter Plot.

replacement surgery. Computer assistance achieves more accurate postoperative alignment in TKA (30-33). A recent meta-analysis concluded that the proportion of $>2^{\circ}$ outliers for coronal alignment of the tibial component was $6.0 \%$ in navigated TKAs and $19.7 \%$ in conventional TKAs, and the proportion of $>3^{\circ}$ outliers was $2.8 \%$ and $9.9 \%$ respectively (33). But contrary to this study there is ample evidence in literature to suggest minimal difference in alignment when comparing computer aided and conventional surgery. Though it is logical to achieve accuracy and expect good outcome. High cost, longer learning curve, and difficulty in procurement precludes the use of this technology. Thus for most routine TKAs a landmark technique is very useful.

But the extra medullary alignment can be unpre- dictable and less reliable due to variability of the landmarks used. To improve accuracy, an anatomical land mark, which is easy to identify, reliable and anatomically constant is essential. We found that the tibialis anterior tendon is a palpable tendon with little variation in its anatomic course. Anatomy textbooks have described the tibialis anterior tendon as passing deep to the inferior extensor retinaculum (34-36).

Abnormal variations regarding the insertion of TA muscle have been reported to be $21.7 \%$ (37). These aberrations vary from attachment to the talus, first metatarsal head or base of proximal phalanx of hallux (38). But the course of tibialis anterior remains unchanged, allowing the use of this tendon as a standard landmark to identify the ankle centre.

Several other references for aligning the extramedullary jigs are available in literature. These include the second metatarsal, extensor hallucis longus tendon, intermalleolar point etc (15-20). However these landmarks are variable and difficult to precisely isolate during surgery. Thus a lot rests on surgeon experience when it comes to appropriate resection. Our study provides a proof that the tibialis anterior tendon has a relatively constant location and position. It can be used to augment surgical accuracy. To counter the difficulty in identifying the tendon during surgery; we mark the tendon preoperatively in an awake patient; where active contraction helps make the tendon prominent and easily palpable even in overweight patient.

Our study does have shortcomings. Firstly, this is a radi- 
ological study with no inclusion of clinical outcomes. Secondly, our study does not provide any information on how accurate the alignment of our TKAs is with the use of this landmark. Nevertheless we do feel that our study further asserts suitability of anatomical landmarks during TKAs. And we also acknowledge that further study is needed to confirm the relation between TKA alignment and use of this anatomical landmark. We are hence running a study to assess the accuracy of post operative alignment of our TKAs when extramedullary alignment jigs are used with tibialis anterior tendon as a distal reference. We conclude that the ankle centre lays 1.5 to $2.5 \mathrm{~mm}$ lateral to the tibialis anterior tendon. This is a reliable fixed point which represents the distal point on the tibial mechanichal axis. We feel this can be safely used in total knee replacement surgery for improving accuracy of alignment. It will also prove an invaluable additional check for coronal alignment.

\section{References}

1. Rodricks DJ, Patil S, Pulido P, Colwell CJ. Press-fit condylar design total knee arthroplasty. Fourteen to seventeen-year follow-up. J Bone Joint Surg Am. 2007;89(1):89-95. doi: 10.2106/JBJS.E.00492. [PubMed: 17200315].

2. Vessely MB, Whaley AL, Harmsen WS, Schleck CD, Berry DJ. The Chitranjan Ranawat Award: Long-term survivorship and failure modes of 1000 cemented condylar total knee arthroplasties. Clin Orthop Relat Res. 2006;452:28-34. doi: 10.1097/01.blo.0000229356.81749.11. [PubMed: 16936585].

3. Kim YH, Park JW, Kim JS, Park SD. The relationship between the survival of total knee arthroplasty and postoperative coronal, sagittal and rotational alignment of knee prosthesis. Int Orthop. 2014;38(2):379-85. doi: 10.1007/s00264-013-2097-9. [PubMed: 24173677].

4. Sikorski JM. Alignment in total knee replacement. J Bone Joint Surg Br. 2008;90(9):1121-7. doi: 10.1302/0301-620X.90B9.20793. [PubMed: 18757949].

5. Jeffery RS, Morris RW, Denham RA. Coronal alignment after total knee replacement.JBone Joint Surg Br. 1991;73(5):709-14. [PubMed:1894655].

6. Ritter MA, Faris PM, Keating EM, Meding JB. Postoperative alignment of total knee replacement. Its effect on survival. Clin Orthop Relat Res. 1994(299):153-6. [PubMed: 8119010].

7. Berend ME, Ritter MA, Meding JB, Faris PM, Keating EM, Redelman R, et al. Tibial component failure mechanisms in total knee arthroplasty. Clin Orthop Relat Res. 2004(428):26-34. [PubMed: 15534515].

8. Teter KE, Bregman D, Colwell CJ. Accuracy of intramedullary versus extramedullary tibial alignment cutting systems in total knee arthroplasty. Clin Orthop Relat Res. 1995(321):106-10. [PubMed: 7497654].

9. Caillouette JT, Anzel SH. Fat embolism syndrome following the intramedullary alignment guide in total knee arthroplasty. Clin Orthop Relat Res. 1990(251):198-9. [PubMed: 2295174].

10. Kalairajah Y, Cossey AJ, Verrall GM, Ludbrook G, Spriggins AJ. Are systemic emboli reduced in computer-assisted knee surgery?: A prospective, randomised, clinical trial.JBone Joint Surg Br. 2006;88(2):198-202. doi:10.1302/0301-620X.88B2.16906. [PubMed:16434523].

11. de Kroon KE, Houterman S, Janssen RP. Leg alignment and tibial slope after minimal invasive total knee arthroplasty: a prospective, randomized radiological study of intramedullary versus extramedullary tibial instrumentation. Knee. 2012;19(4):270-4. doi: 10.1016/j.knee.2011.04.007. [PubMed: 21601462].
12. Reed MR, Bliss W, Sher JL, Emmerson KP, Jones SM, Partington PF. Extramedullary or intramedullary tibial alignment guides: a randomised, prospective trial of radiological alignment. J Bone Joint Surg Br. 2002;84(6):858-60. [PubMed: 12211678].

13. Mahaluxmivala J, Bankes MJ, Nicolai P, Aldam CH, Allen PW. The effect of surgeon experience on component positioning in 673 Press Fit Condylar posterior cruciate-sacrificing total knee arthroplasties. J Arthroplasty. 2001;16(5):635-40. doi: 10.1054/arth.2001.23569. [PubMed: 11503124].

14. Petersen TL, Engh GA. Radiographic assessment of knee alignment after total knee arthroplasty. J Arthroplasty. 1988;3(1):67-72. [PubMed: 3361322].

15. Fang DM, Ritter MA, Davis KE. Coronal alignment in total knee arthroplasty: just how important is it? J Arthroplasty. 2009;24(6 Suppl):3943. doi: 10.1016/j.arth.2009.04.034. [PubMed:19553073].

16. Rajadhyaksha AD, Mehta $\mathrm{H}$, Zelicof SB. Use of tibialis anterior tendon as distal landmark for extramedullary tibial alignment in total knee arthroplasty: an anatomical study. Am J Orthop (Belle Mead NJ). 2009;38(3):E68-70. [PubMed: 19377655].

17. Schneider M, Heisel C, Aldinger PR, Breusch SJ. Use of palpable tendons for extramedullary tibial alignment in total knee arthroplasty. J Arthroplasty. 2007;22(2):219-26. doi: 10.1016/j.arth.2006.04.023. [PubMed: 17275637].

18. Simmons EJ, Sullivan JA, Rackemann S, Scott RD. The accuracy of tibial intramedullary alignment devices in total knee arthroplasty.J Arthroplasty. 1991;6(1):45-50. [PubMed: 2016608].

19. Tew M, Waugh W. Tibiofemoral alignment and the results of knee replacement. J Bone Joint Surg Br. 1985;67(4):551-6. [PubMed: 4030849].

20. Lotke PA, Ecker ML. Influence of positioning of prosthesis in total knee replacement. J Bone Joint Surg Am. 1977;59(1):77-9. [PubMed: 833180].

21. Hsu RW, Himeno S, Coventry MB, Chao EY. Normal axial alignment of the lower extremity and load-bearing distribution at the knee. Clin Orthop Relat Res. 1990(255):215-27. [PubMed: 2347155].

22. Johnson F, Leitl S, Waugh W. The distribution of load across the knee. A comparison of static and dynamic measurements. J Bone Joint Surg Br. 1980;62(3):346-9. [PubMed: 7410467].

23. Kettelkamp DB, Chao EY. A method for quantitative analysis of medial and lateral compression forces at the knee during standing. Clin Orthop Relat Res. 1972;83:202-13. [PubMed: 5014814].

24. Hood RW, Vanni M, Insall JN. The correction of knee alignment in 225 consecutive total condylar knee replacements. Clin Orthop Relat Res. 1981(160):94-105. [PubMed: 7285443].

25. Bargren JH, Blaha JD, Freeman MA. Alignment in total knee arthroplasty. Correlated biomechanical and clinical observations. Clin Orthop Relat Res. 1983(173):178-83. [PubMed: 6825330].

26. Hvid I, Nielsen S. Total condylar knee arthroplasty. Prosthetic component positioning and radiolucent lines. Acta Orthop Scand 1984;55(2):160-5. [PubMed: 6711282].

27. Moreland JR, Thomas RJ, Freeman MA. ICLH replacement of the knee: 1977 and 1978. Clin Orthop Relat Res. 1979(145):47-59. [PubMed: 535289].

28. Laskin RS, Turtel A. The use of an intramedullary tibial alignment guide in total knee replacement arthroplasty. Am J Knee Surg. 1989;2:123.

29. Dennis DA, Komistek RD, Kim RH, Sharma A. Gap balancing versus measured resection technique for total knee arthroplasty. Clin Orthop Relat Res. 2010;468(1):102-7. doi: 10.1007/s11999-009-1112-3. [PubMed: 19789934].

30. Bathis H, Perlick L, Tingart M, Luring C, Zurakowski D, Grifka J Alignment in total knee arthroplasty. A comparison of computerassisted surgery with the conventional technique. J Bone Joint Surg Br. 2004;86(5):682-7. [PubMed: 15274263].

31. Chauhan SK, Scott RG, Breidahl W, Beaver RJ. Computer-assisted knee arthroplasty versus a conventional jig-based technique. A ran- 
domised, prospective trial. J Bone Joint Surg Br. 2004;86(3):372-7. [PubMed: 15125124].

32. Chin PL, Yang KY, Yeo SJ, Lo NN. Randomized control trial comparing radiographic total knee arthroplasty implant placement using computer navigation versus conventional technique. J Arthroplasty. 2005;20(5):618-26. doi: 10.1016/j.arth.2005.04.004. [PubMed 16309998].

33. Fu Y, Wang M, Liu Y, Fu Q. Alignment outcomes in navigated total knee arthroplasty: a meta-analysis. Knee Surg Sports Traumato Arthrosc. 2012;20(6):1075-82. doi: 10.1007/s00167-011-1695-6. [PubMed: 22002300].
34. Moore KL, Dalley AF, Agur AMR. Clinically oriented anatomy. Lippincott Williams \& Wilkins; 2013.

35. Rosse C, Rosse PG. In: Hollinshead's Textbook of Anatomy. Rosse C, Rosse PG, editors. New York: Lippincott Raven; 1997. pp. 337-490.The free lower limb: thigh, leg and foot.

36. Sinclair DC. In: Cunningham's Textbook of Anatomy. Sinclair DC, editor. Toronto: Oxford University Press; 1991. Muscle and fascia.

37. Luchansky E, Paz Z. Variations in the insertion of tibialis anterior muscle. Anat Anz. 1986;162(2):129-36. [PubMed: 3789411].

38. Gray H, Standring S. Gray's anatomy: the anatomical basis of clinical practice, 40th edn. Churchill-Livingstone. Elsevier; 2008. 